\title{
Evaluation of the Virus Counter ${ }^{\circledR}$ for rapid baculovirus quantitation
}

\author{
Matthew M. Ferris ${ }^{a}, d$, Patricia C. Stepp ${ }^{a}$, Kirk A. Rannoa, Wafaa Mahmoud ${ }^{b}$, Elizabeth \\ Ibbitson $^{\mathrm{b}}$, James Jarvis ${ }^{\mathrm{b}}$, Manon M.J. Cox ${ }^{\mathrm{b}}$, Kurt Christensen ${ }^{\mathrm{c}}$, Heather Votaw ${ }^{\mathrm{c}}$, Dean $\mathrm{P}$. \\ Edwards $^{\mathrm{C}}$, and Kathy L. Rowlen ${ }^{\mathrm{a}}$ \\ alnDevR, Inc., 2100 Central Ave., Suite 106, Boulder, CO 80301, USA \\ bProtein Sciences Corp., 1000 Research Parkway, Meriden, CT, 06450, USA \\ 'Baylor College of Medicine, Baculovirus/Monoclonal Antibody Facility, Dan L. Duncan Cancer \\ Center, Mail Stop 130, Rm R551E, 1 Baylor Plaza, Houston, TX, 77030, USA
}

\begin{abstract}
The utility of a new instrument for rapid virus quantitation, the Virus Counter, was evaluated in a blind study conducted at three sites. This instrument is a substantially improved version of the original academic research instrument described previously by Stoffel $e$ t al. (2005a). The addition of hydrodynamic focusing, a self-contained fluidics system and customized software for system control and data analysis has resulted in a commercially viable and available design. Baculovirus samples were provided by Protein Sciences Corporation and blinded to InDevR and Baylor College of Medicine. Protein Sciences Corporation and Baylor College of Medicine analyzed the samples by plaque assay and InDevR analyzed the samples using the Virus Counter. Serial dilution of stock viruses into growth media and buffer allowed for comparison of measured versus intended concentrations. Direct log-scale comparison between pooled Virus Counter results and pooled plaque assay results indicated a linear relationship (slope $=1.1 \pm 0.2, \mathrm{R}^{2}=0.86$ ) with statistically significant Pearson correlation $(r=0.93, p<0.001)$.
\end{abstract}

\section{Keywords}

baculovirus; plaque assay; Virus Counter; recombinant protein; virus quantitation

\section{Introduction}

Recombinant protein production is performed commonly using the baculovirus expression vector system (BEVS) (Hitchman et al., 2007; Holtz et al., 2003; Kost et al., 2005; Wang et al., 2006). The BEVS offers advantages over other methods for the production of proteins used in pharmaceuticals, vaccines and pesticides (Cox, 2005; Cox, 2008; Hopkins and

\footnotetext{
(C) 2010 Elsevier B.V. All rights reserved.

${ }^{d}$ Correspondence to: Matthew M. Ferris, PhD, InDevR, Inc., 2100 Central Ave., Suite 106, Boulder, CO 80301. Phone: 303-402-9100. Fax: 303-402-9300. ferris@indevr.com.

Publisher's Disclaimer: This is a PDF file of an unedited manuscript that has been accepted for publication. As a service to our customers we are providing this early version of the manuscript. The manuscript will undergo copyediting, typesetting, and review of the resulting proof before it is published in its final citable form. Please note that during the production process errors may be discovered which could affect the content, and all legal disclaimers that apply to the journal pertain.

Conflict of Interest

InDevR, Inc. is a for-profit entity and four of the eleven authors are employees of the company.
} 
Esposito, 2009; Nettleship et al., 2010; Trowitzsch et al., 2010). To best utilize the BEVS it is necessary to accurately quantify virus concentration during viral stock preparation and recombinant protein production. In many situations, researchers and production facilities would be able to make more informed decisions and better optimize their process if virus concentrations could be determined quickly. A rapid determination of virus concentration, whether it be total virus particle concentration or infectious dose, would be beneficial throughout production when there is not enough time to wait days or longer for results from standard assays. A rapid analysis method would allow for semi real-time monitoring to identify any potential issues and optimization of the process. For example, losses could be minimized if failed virus amplification were identified early (Dutton, 2008). This could be determined by monitoring total particle count and does not require infectious count results. To address these needs, the Virus Counter's ability to provide rapid baculovirus quantitation was evaluated relative to the plaque assay in a blind study conducted at three sites.

The gold standard for viral titering is the plaque assay, which provides viral titer based on infected cells producing plaques. Plaque assay results provide a concentration of infectious virus particles or plaque-forming units ( $\mathrm{pfu} / \mathrm{mL})$. The plaque assay for baculovirus requires between 4 to 10 days to complete, with research efforts commonly bottlenecked by this step. Also, many facilities have established their own protocol for plaque assays with slight variations throughout which have been proven to influence the viral titer accuracy (Roldao et al., 2009). A more rapid assay could significantly streamline research and development efforts. While there are alternative analytical methods available, such as $50 \%$ tissue culture infectivity dose assay $\left(\mathrm{TCID}_{50}\right)$ (Darling et al., 1998), end-point dilution assays (Lynn, 1992), transmission electron microscopy (TEM) (Borsheim et al., 1990), quantitative PCR (qPCR) (Lo and Chao, 2004) and traditional flow cytometry (Shen et al., 2002), each of these methods has a set of limitations and none are ideal as a rapid and inexpensive alternative to the plaque assay. The limitations of current assays have motivated researchers to develop new analytical methods with the goals of addressing the market need for a rapid virus quantitation assay that is linear, precise and robust (Kalbfuss et al., 2008).

Additionally, ideal methods would be easy to use and allow for high sample throughput (Mulvania et al., 2004). The Virus Counter, which represents a new method for baculovirus quantitation, was evaluated for its ability to meet these needs.

The Virus Counter is a specialized flow cytometer designed to provide rapid virus quantitation for liquid samples. The instrument and assay represent a time and cost-effective alternative for determination of baculovirus concentration. While an early academic prototype using the same detection principle was presented previously by Stoffel $e t$ al. (2005a), drastic improvements have since been made to produce a commercially available and viable instrument. These improvements have produced a system that is much more efficient, accurate and easy to use with a well-defined assay protocol. The Virus Counter has transitioned from a laser table with attached components in a dark room controlled by a graduate student to a robust and self-contained design that can be operated by a laboratory technician. Specifically, the Virus Counter utilizes hydrodynamic focusing of the sample instead of direct flow through a capillary to improve detection efficiency from $17 \%$ to $\sim 100 \%$ (Stoffel et al., 2005a). Additionally, the commercial Virus Counter incorporates a completely self-contained fluidics system that is capable of real-time control and measurement of sample flow rates as well as intuitive software for integrated system control and data analysis. In the Virus Counter assay, intact virus particles are quantified by detecting fluorescence from particles containing colocalized proteins and nucleic acids (Stoffel et al., 2005b). Two dyes, one specific for proteins and one specific for nucleic acids, are used to stain samples in a 30-minute incubation step. This unique, non-specific staining process eliminates the need for target-specific reagents which are used in traditional flow cytometry (Kuzushima et al., 1999; Schulze-Horsel et al., 2008). The removal of a multi- 
step antibody staining procedure increases the ease of use for the operator and reduces assay costs. The instrument quantifies the concentration of virus particles $(\mathrm{vp} / \mathrm{mL})$ based on the number of events occurring simultaneously on the two distinct fluorescence channels and the measured sample flow rate. Similar to TEM, the Virus Counter reports a total virus particle concentration (Borsheim et al., 1990), which tends to be higher than infectivity assay results but lower than results obtained by qPCR.

A comparison of baculovirus quantitation results from the Virus Counter, relative to plaque assay, was conducted in this collaborative study involving InDevR, Protein Sciences Corporation (PSC) and the Baculovirus/Monoclonal Antibody Facility at the Baylor College of Medicine (BCM). Virus Counter results are evaluated relative to plaque assay results from these two labs, with each lab performing their own unique plaque assay protocol.

\section{Materials and methods}

\subsection{Virus samples}

Protein Sciences Corporation (Meriden, CT, USA) donated and prepared all samples for this study. A recombinant baculovirus, transfected into Sf-9 cells, was propagated and scaled up in expres $\mathrm{Sf}+$ cells to virus passage P5. Virus stocks were prepared using a $500 \mathrm{~mL}$ culture of expres $\mathrm{Sf}+$ insect cells (Spodoptera frugiperda) grown in Protein Sciences Fortified Media (PSFM) using a $3 \mathrm{~L}$ spinner flask. expresSf+ insect cells and PSFM are proprietary to Protein Sciences Corporation (PSC, Meriden, CT, USA). Cultures were allowed to grow for 18-24 hours to a viable cell density of $\sim 1.5 \times 10^{6}$ cells $/ \mathrm{mL}$ for infection at a multiplicity of infection (MOI) of $0.1 \mathrm{pfu} / \mathrm{cell}$ using a virus stock of $\sim 5 \times 10^{7} \mathrm{pfu} / \mathrm{mL}$. This MOI is commonly used for virus amplification (Tsai et al., 2007). After infection, the culture was incubated at $27^{\circ} \mathrm{C}$ on a stir plate set at $100 \mathrm{rpm}$. Harvest time (68-77 hours post infection, hpi) was determined when a late stage of infection in the majority of cells was indicated based on cell morphology characteristics (e.g., visible budded virus, cell lysis) and a viable cell density of $<50 \%$. All cell density and viability measurements were made using the CEDEX AS20 Cell Analyzer (Innovatis, Bielefeld, Germany). At harvest, the culture was centrifuged for $15 \mathrm{~min}$ at $4500 \mathrm{rpm}$ and $4^{\circ} \mathrm{C}$. The virus stock (i.e. supernatant) was then decanted and stored in the dark at $4^{\circ} \mathrm{C}$.

Virus stocks used in this study were initially plaque titered within 2 weeks of the stock's preparation and diluted samples were prepared 1 month after stock production. Baculovirus stocks remain stable for up to 50 days while stored at $4^{\circ} \mathrm{C}$ (Jorio et al., 2006) and Protein Sciences Corporation considers the virus stable for 8 weeks from the date of production. The stock used to prepare the diluted samples $(1 \mathrm{a}-7 \mathrm{a}$ and $1 \mathrm{~b}-7 \mathrm{~b})$ had an initial plaque assay titer of $1.7 \times 10^{8} \mathrm{pfu} / \mathrm{mL}$. Dilutions within each series were limited to those that would produce a virus concentration between $1 \times 10^{5}$ and $1 \times 10^{9} \mathrm{pfu} / \mathrm{mL}$. Dilution series $(N=7$ in each series) of this stock were prepared in two different diluents. Diluent "a" was PSFM and diluent "b" was InDevR's Sample Dilution Buffer (SDB) (InDevR, Boulder, CO, USA). Samples within each dilution series were blinded and labeled with a sample ID and stored at $4^{\circ} \mathrm{C}$ until distribution to Baylor College of Medicine and InDevR. The positive control was a baculovirus stock (P5) of another cell membrane protein. It was prepared at the same time and under the same conditions used to prepare the stock from which the dilution series were prepared. Both sterile serum-free media (PSFM) and membrane filtered InDevR SDB were used as negative (-) controls. Samples and controls were shipped on ice and stored at $4{ }^{\circ} \mathrm{C}$ until analysis. Protein Sciences Corporation and Baylor College of Medicine performed plaque assays on the samples, while InDevR analyzed the samples using the Virus Counter. All results were sent to Protein Sciences Corporation where they were compiled, un-blinded and subsequently shared for analysis and discussion. 


\subsection{Virus quantitation by Protein Sciences Corporation}

Virus titers were expressed in plaque forming units (pfu/ml) as described by Summers and Smith (1987) and reviewed by O'Reilly et al. (1994). Each sample, as well as each dilution of each sample, was tested in triplicate. Wild-type baculovirus $\left(\sim 1.0 \times 10^{8}\right)$ was included as an assay positive control $\left(N=3,10^{-6}\right.$ dilution), and a negative control consisting of cells only was also included $(N=3)$.

Sf-9 insect cells were grown in Grace's supplemented insect media (TNM-FH) (SAFC Biosciences, Lenexa, KS, USA) to obtain a culture at $\geq 1 \times 10^{6}$ cells $/ \mathrm{mL}$, (pre-grown from starting viable cell density of $0.75 \times 10^{6}$ cells $/ \mathrm{mL}$ in TNM-FH media for less than 30 hours). Cells were added to each $60 \mathrm{~mm}$ bacteriological petri dish $\left(\sim 2.5 \times 10^{6}\right.$ cells $)$ (BD Biosciences, Franklin Lakes, NJ, USA) and incubated at room temperature for $60 \mathrm{~min}$ to allow cells to attach.

For each virus sample, appropriate dilutions were prepared using TNM-FH media. Standard dilutions were $10^{-5}$ and $10^{-6}$, however, additional dilutions (e.g., $10^{-2}-10^{-4}$ ) were used for samples of expected low titer. After $60 \mathrm{~min}$, the media was removed, without disturbing the cell layer. Plates were inoculated with $1 \mathrm{~mL}$ of the diluted virus sample of each selected dilution in 3 appropriately labeled dishes. Positive and negative control dishes were inoculated at the same time with $1 \mathrm{~mL}$ of the appropriate control. Each dish was immediately rocked 3-5 times to ensure uniform distribution of the virus and then incubated at room temperature for $60 \mathrm{~min}$ with manual rocking every $15 \mathrm{~min}$. A $50 \%$ mixture of $2 \mathrm{X}$ Grace's insect media/Agarose overlay solution was prepared at $40^{\circ} \mathrm{C}$ and then added to each dish, avoiding disturbance of the cell layer. Dishes were allowed to rest upright for $45 \mathrm{~min}$ to allow the agarose overlayer to solidify. Dishes were then inverted inside a plastic container with a dampened absorbent towel and incubated at $27^{\circ} \mathrm{C}$ for 6 days after which dishes were examined under low magnification with a Bausch and Lomb stereo zoom microscope (Bausch and Lomb, Rochester, NY, USA) to count the number of plaques.

Plaque assay results (pfu/mL) were determined by multiplying the average number of plaques by the appropriate dilution factor. Only counts between 30 and 300 plaques per dish were deemed statistically significant. Negative control dishes were confirmed to not contain any plaques or microbial contamination.

\subsection{Virus quantitation by Baylor College of Medicine}

Recombinant baculovirus samples (diluted samples along with the positive and negative controls) were received from Protein Sciences Corporation at $4^{\circ} \mathrm{C}$ and immediately transferred to a $4^{\circ} \mathrm{C}$ cold room where they were stored in the dark until analysis. Plaque assays conducted at Baylor College of Medicine were performed using modifications of the plaque assay from Summers and Smith (1987), similar to Protein Sciences Corporation. Low passage (<30) Sf-9 cells, grown in Grace's insect media plus 0.1\% Pluronic F68 (Invitrogen, Carlsbad, CA, USA) and 10\% heat-inactivated fetal bovine serum (Sigma, St. Louis, MO, USA), were added to $60 \mathrm{~mm}$ Easy Grip ${ }^{\mathrm{TM}}$ cell culture dishes (BD Biosciences, Franklin Lakes, NJ, USA) at $1.25 \times 10^{6}$ cells per dish and allowed to attach for $60 \mathrm{~min}$ at $27^{\circ} \mathrm{C}$. Nine dishes were prepared for each sample to be titered. One dish of Sf-9 cells was included as a negative control for each assay.

Viral samples were diluted serially in serum-free Grace's insect media plus Pluronic F68 to $4 \mathrm{~mL}$ final volumes of dilutions at $10^{-5}, 10^{-6}$, and $10^{-7}$. After $60 \mathrm{~min}$, the media was removed from the cells and replaced with $1 \mathrm{~mL}$ per plate of the appropriate viral dilution. All dilutions were plated in triplicate for these assays. Dishes were rocked gently for $60 \mathrm{~min}$ in a $27^{\circ} \mathrm{C}$ incubator. A $50 \%$ mixture of $2 \mathrm{X}$ Grace's insect media/Agarose overlay solution was prepared at $37^{\circ} \mathrm{C}$ and cooled at room temperature for $20 \mathrm{~min}$ before use. At the end of 
the 60 min incubation, the dishes were transferred from the incubator to the laminar flow hood, where the viral inoculum was aspirated from the dishes, in sets of 3 , and $4 \mathrm{~mL}$ of the Grace's/Agarose overlay solution was added to each dish. The dishes were vented for $5 \mathrm{~min}$, wrapped individually in Parafilm, and moved to a $27^{\circ} \mathrm{C}$ incubator for 7 days.

After 7 days, dishes were unwrapped and $1.3 \mathrm{~mL}$ of $0.4 \%$ trypan blue solution (Invitrogen, Carlsbad, CA, USA) was added on top of the agarose in each dish and incubated for $5 \mathrm{~min}$ in the hood. The trypan blue solution was aspirated completely, and the dishes were placed back into the incubator for a minimum of 2 hours before blue-stained plaques were visually counted on an inverted Olympus CKX41 microscope (Olympus, Center Valley, PA, USA). Viral concentrations were calculated using the average count from 3 dishes of the same dilution and multiplying that number by the dilution factor (O'Reilly et al., 1994). The final concentration of each virus was calculated by taking the average titer from each of the 3 dilutions, excluding any set of titers at 1 dilution if the average was $<1 \mathrm{pfu} / \mathrm{dish}$. Having no prior knowledge of the titers of the supplied samples, Baylor College of Medicine used their standard $10^{-5}-10^{-7}$ dilutions only. These dilutions resulted in fewer statistically significant results than Protein Sciences Corporation due to some plates having very few or no plaques present.

\subsection{Virus quantitation by InDevR}

Samples and controls supplied by Protein Sciences Corporation were analyzed at InDevR using the Virus Counter instrument and assay. Samples were stored at $4^{\circ} \mathrm{C}$ until use and were prepared using reagents and methods supplied by InDevR according to assay guidelines. Briefly, the Virus Counter instrument was validated each day using a nonbiological positive control to ensure proper instrument function and performance. Virus samples and controls were prepared by first diluting them 10X in SDB and staining $200 \mu \mathrm{L}$ of diluted sample with a working Combo Dye solution (1:2, dye:sample ratio) (InDevR, Boulder, CO, USA). Daily samples were stained and allowed to incubate for $30 \mathrm{~min}$ at room temperature prior to analysis. A positive control was used to guide the development of sample and matrix-specific settings for the Virus Counter and these settings were used for the analysis of all remaining samples and controls. All samples and controls were analyzed multiple times $(N \geq 5)$ over multiple days $(N=3)$ by multiple users $(N=3)$ using multiple Virus Counter instruments $(N=3)$. Settings were validated each day using the positive control and inter-sample washes were used between all samples to prevent sample carry over. Each sample required approximately $10 \mathrm{~min}$ for analysis.

The Virus Counter's Instrument Quantification Limit (IQL), which defines the lowest concentration that the instrument can report with statistical confidence, is $\sim 5 \times 10^{5} \mathrm{vp} / \mathrm{mL}$. The linear dynamic range for the assay is typically $5 \times 10^{5}$ to $1 \times 10^{9} \mathrm{vp} / \mathrm{mL}$ for viruses in a clean matrix. For viruses in more complex matrices, such as growth media, a Sample Quantification Limit (SQL) must be determined. Generally, the SQL is greater than or equal to the IQL. The SQL is determined experimentally from replicate analyses of negative controls using Equation 1:

$$
S Q L=X_{n e g}+t_{99 \%}\left(\sigma_{n e g}\right)
$$

where $X_{\text {neg }}$ is the mean value for $N$ measurements of a negative control, $t_{99 \%}$ is the statistical t value for $N-1$ degrees of freedom at $99 \%$ confidence, and $\sigma_{\text {neg }}$ is the measured standard deviation for the negative controls. For this study, negative controls were stained and analyzed each day $(N=5)$ to determine the SQL. 
All Virus Counter results were compiled, corrected for the initial 10X dilution in SDB and average results were reported to Protein Sciences Corporation. Additionally, SQL values were reported for each of the diluents along with instructions to not include any results for which the average value was less than the corresponding diluent's SQL.

\subsection{Statistical Analysis}

Correlation analyses of assay results determined the linear association between the log-scale results of each assay. Pearson correlation coefficients ( $r$ ) and $p$-values were determined using GraphPad Prism 5 software (GraphPad Software, La Jolla, CA, USA). Statistical significance for Pearson correlation analysis was determined when $\mathrm{p}$ values were less than 0.05. Linear regression analysis was performed using Microsoft Excel 2007.

\section{Results}

Blind samples were provided in two dilution mediums and were labeled $1 \mathrm{a}-7 \mathrm{a}$ and $1 \mathrm{~b}-7 \mathrm{~b}$ to distinguish the two sets. InDevR analyzed each sample using three different users and multiple instruments over a three-day period. Protein Sciences Corporation and Baylor College of Medicine each performed plaque assays in triplicate for each sample with each site performing their own variation of the plaque assay. The positive control had a reported titer of $1.7 \times 10^{8} \mathrm{pfu} / \mathrm{mL}$. The Virus Counter result for the positive control $\left(1.1 \times 10^{9} \mathrm{vp} /\right.$ $\mathrm{mL}$ ) was $\sim 10 \mathrm{X}$ greater than the reported plaque assay titer while the measured plaque assay results from Protein Sciences Corporation and Baylor College of Medicine for the positive control were lower $\left(8 \times 10^{7}\right.$ and $5.7 \times 10^{7} \mathrm{pfu} / \mathrm{mL}$, respectively) than the reported titer.

Negative controls were used to determine the Virus Counter's SQL values for each dilution medium, and were found to be $3.1 \times 10^{6} \mathrm{vp} / \mathrm{mL}$ for PSFM and $7.8 \times 10^{5} \mathrm{vp} / \mathrm{mL}$ for SDB. A summary of samples and results is provided in Table 1. All measured Virus Counter results, equal to or lower than the SQL, were not included in the quantitative inter-assay comparison since they were not statistically different than the negative control. Plaque assay results too low to quantify accurately (as determined by each lab's protocol) were not reported and are indicated by a dash in Table 1. It should be noted that Protein Sciences Corporation was able to quantify all samples in the study given their prior knowledge of the samples and subsequent use of additional dilutions $\left(10^{-2}-10^{-4}\right)$ in their plaque assays. Baylor College of Medicine was unable to observe plaque formation in these low titer samples due to the use of their standard dilutions series $\left(10^{-5}-10^{-7}\right)$.

Results from InDevR and Baylor College of Medicine were gathered and reported to Protein Sciences Corporation knowing only the sample ID and reported concentrations for the controls. Dilution factors and intended concentrations were provided by Protein Sciences Corporation only after receiving results from InDevR and Baylor College of Medicine. Unblinding of the samples revealed that samples 1a-7a were diluted in PSFM and that samples $1 b-7 b$ were diluted in InDevR's SDB. The intended titer values listed for each sample are based on the plaque assay titer and the dilution factor used to prepare each sample from the virus stock. All measured analysis results shown in Table 1 are the mean of the replicates analyzed by each lab, with listed error representing $\pm 1 \sigma$ from the mean.

The linear fit of each lab's measured assay results, relative to the intended titer, is shown in Figure 1 for the samples 1a-7a (PSFM media). Virus Counter values less than the measured SQL in the PSFM media are shown in Figure 1 (hollow triangles) but were not included in the linear regression analysis of the results. A logarithmic scale is used in Figure 1 to allow visualization of results over the broad range of sample concentrations analyzed in this study. Pearson correlation analysis revealed that results from the Virus Counter $(r=0.94, p<0.01)$ and Baylor College of Medicine $(r=0.99, p<0.001)$ both correlated well with the intended titer values while results from Protein Sciences Corporation had the lowest correlation $(r=$ 
$0.90, \mathrm{p}<0.01)$. All assays correlated significantly $(\mathrm{p}<0.01)$ with the intended titer according to the Pearson analysis. Linear regression analysis revealed varying results for the Virus Counter (slope of $1.2 \pm 0.1, \mathrm{R}^{2}=1.00$ ), Baylor College of Medicine (slope of $0.81 \pm$ $0.07, \mathrm{R}^{2}=0.97$ ) and Protein Sciences Corporation (slope of $1.1 \pm 0.2, \mathrm{R}^{2}=0.81$ ). The relative error in the Virus Counter's reported results ranged from 0.2 to $0.4 \log \mathrm{vp} / \mathrm{mL}$ units, while Baylor College of Medicine and Protein Sciences Corporation's relative error was from 0.01 to $0.1 \log$ pfu/mL units. However, it should be noted that the Virus Counter results represent replicate analysis by 3 different operators, on 3 different instruments, over multiple days. The plaque assay results represent the work of fewer technicians $(\mathrm{N} \leq 2)$ and the maximum number of replicates conducted on the same day was 3 .

Figure 2 is a log-log correlation plot for samples $1 b-7 b$, which were prepared in SDB. A linear regression fit of the Virus Counter results to the intended titer was obtained with an $\mathrm{R}^{2}$ value of 1.00 , and a slope of $1.32 \pm 0.04$. Plaque assay results for samples $1 \mathrm{~b}-7 \mathrm{~b}$ were different from those for samples 1a-7a in that Baylor College of Medicine's measured results had an increased slope value of $1.0 \pm 0.3$, but a decreased coefficient of determination $\left(\mathrm{R}^{2}=0.82\right)$ while Protein Sciences Corporation's results had a markedly decreased slope of $0.5 \pm 0.1$ with an increased $\mathrm{R}^{2}$ value of 0.85 . The Pearson correlation coefficients increased for the Virus Counter $(r=1.0, \mathrm{p}<0.001)$ and Protein Sciences Corporation $(r=0.92, p<0.01)$ while results from Baylor College of Medicine had a decreased correlation $(r=0.90, p<0.05)$, but all were shown to be significantly correlated ( $p$ $<0.05$ ) to the intended titer. The plaque assay results for all samples are considered within a normal range given the generally accepted error level of the assay (Knipe and Howley, 2007; Mahy and Kangro, 1996).

Direct correlation between Virus Counter and plaque assay results was evaluated by combining the plaque assay titer values from Protein Sciences Corporation and Baylor College of Medicine. As shown in Figure 3, linear regression analysis of the log of the average Virus Counter results ( $\mathrm{vp} / \mathrm{mL}$ ) versus $\log$ of the average plaque assay results (pfu/ $\mathrm{mL}$ ) yields reasonable fit, with a slope of $1.1 \pm 0.2$ and an $\mathrm{R}^{2}$ value of 0.86 . Statistically significant correlation was determined by Pearson correlation analysis $(r=0.93, p<0.001)$. Figure 3 includes data for both diluents' sample sets. The error associated with the Virus Counter results represents that of multiple users $(N=3)$, instruments $(N=3)$, and days $(N=$ $3)$. Likewise, the combined plaque assay results from Protein Sciences Corporation and Baylor College of Medicine represent multiple users $(N=3)$ multiple laboratories $(N=2)$ over multiple weeks time. Likewise, the combined plaque assay results represent the normal protocol variation of the assay practiced by each laboratory.

\section{Discussion}

Current baculovirus quantitation methodologies include plaque assay, $\mathrm{TCID}_{50}$, quantitative PCR and TEM. Infectious assays are time consuming with the plaque assay taking up to 10 days and TCID $_{50}$ taking up to one week. TEM and qPCR are faster, both taking only hours to complete and providing results in virus particles per milliliter $(\mathrm{vp} / \mathrm{mL})$ and genome copies per milliliter ( $\mathrm{gc} / \mathrm{mL})$, respectively. While TEM and qPCR significantly shorten the analysis time, there are still shortcomings to using these for baculovirus quantitation. TEM is relatively expensive and few laboratories have access to facilitate routine TEM analysis. Likewise, qPCR requires primers specific to each virus of interest and amplifies all target nucleic acid, whether from an intact virion or free nucleic acids in solution (Borsheim et al., 1990; Lo and Chao, 2004).

The Virus Counter offers results in virus particles per milliliter $(\mathrm{vp} / \mathrm{mL})$ with a 30-minute preparation time and sample analysis in less than $10 \mathrm{~min}$. The Combo Dye used is not virus- 
specific and can be used with a wide variety of viruses, including baculovirus, at a significantly decreased cost compared to TEM. Our blind study has shown that the Virus Counter provides results that correlate in a statistically meaningful way $(r=0.93, p<0.001)$ with average plaque assay results from two different laboratories. Furthermore, the average standard error of the mean for combined log results was lower for Virus Counter $(0.09 \pm$ $0.03 \mathrm{vp} / \mathrm{mL})$ than the plaque assay $(0.14 \pm 0.06 \mathrm{pfu} / \mathrm{mL})$.

The negative controls were required to ensure that the events quantified by the Virus Counter were not due to matrix interferences. The fact that the measured values of the negative controls, PSFM and SDB, were within an order of magnitude of the IQL indicates that neither media presented significant matrix interference issues. As expected, PSFM had an SQL value greater than that for SDB since PSFM is a complex growth medium and SDB is a simple buffer solution. The positive control, identified as a high titer stock similar in approximate titer and composition to that used to prepare the unknown dilutions, was used to establish quantitation settings for the Virus Counter.

A detail not apparent from Table 1 is the analysis time for each assay. Virus Counter analysis by InDevR was completed in 3 days. This time period included running each sample multiple times on multiple instruments over a 3-day period. Analysis of a single sample required only $\sim 10 \mathrm{~min}$. Plaque assay analysis requires longer times to allow for infection and the formation of plaques. Baylor College of Medicine was able to return results to Protein Sciences Corporation within 3 weeks of receiving samples and Protein Sciences Corporation's analysis required $\sim 2$ weeks. Baylor College of Medicine and Protein Sciences Corporation's mean measured titer values were an average of $11 \mathrm{X}$ and $25 \mathrm{X}$ less than the intended titers, while Virus Counter results were an average of $3 \mathrm{X}$ greater than the intended titer values. This is not surprising given that the Virus Counter quantifies all virus particles while the plaque assay only counts infectious virions.

This study also highlights the variability of baculovirus titers determined by plaque assay, often considered the gold standard for virus quantitation. Protein Sciences Corporation and Baylor College of Medicine have well-established and validated protocols for their plaque assay methods, but obtained different baculovirus titers. Both methods have differences that could account for the variation between the two facilities' measured results. Baylor College of Medicine uses half the cell density $\left(1.25 \times 10^{6} \mathrm{cells} / \mathrm{dish}\right)$ for virus inoculation than Protein Sciences Corporation $\left(2.5 \times 10^{6}\right.$ cells/dish). Also, Protein Sciences Corporation prefers a manual rocking method over Baylor College of Medicine's automatic rocking after the virus has been added to the cells. Another important difference is the procedure once the agarose overlay has been prepared. Baylor College of Medicine allows the mixture to cool for $20 \mathrm{~min}$, then adds the solution to the dish and after 5 min wraps the dish in parafilm and incubates the dishes upright. Protein Sciences Corporation allows the solution to solidify in the dish for $45 \mathrm{~min}$ while in the hood before placing the dishes inverted in the incubator. It has been determined previously that non-efficient virus/cell contacts due to cell concentration at the time of infection and agarose overlay temperature can affect the amount of plaques that form causing a reduced titer (Roldão et al., 2009). While both of these protocols are valid for baculovirus quantitation, the small differences in methods could certainly manifest in variation in results. We believe that these minor differences between labs are common and that the observed variation in plaque assay results is representative of inter-lab variation for the assay.

Baylor College of Medicine and Protein Sciences Corporation also observed a difference in the Pearson correlation coefficient and linear fit between the two suspension matrices, PSFM and SDB. While these differences cannot be attributed to a single factor, they are most likely due to an intricate combination of assay differences, user error and matrix 
differences. These results indicate that the plaque assay has several factors that may affect the accuracy and precision of resulting viral titers (Roldão et al., 2009), and does not always represent the gold standard that many assume.

The data presented in this study show that the Virus Counter is capable of providing rapid baculovirus quantitation with results that significantly correlate $(r=0.93, p<0.001)$ with plaque assay titer values. In addition, the Virus Counter exhibited better correlation with the intended titer value ( $r=0.94$ for PSFM and $r=1.0$ for SDB) than did the plaque assay, indicating greater accuracy. Additionally, precision for the Virus Counter was better than that of the combined plaque assay, as indicated by a lower average standard error of the mean. Overall, the data indicate that the Virus Counter provides a reliable means to quantify baculovirus samples above $\sim 10^{6} \mathrm{vp} / \mathrm{mL}$ in a fraction of the time required to conduct a plaque assay.

\section{Acknowledgments}

This work was supported by the National Institutes of Health, National Institute of Allergy and Infectious Diseases (NIH/NIAID; grant \#: 5 R44 AI068270-04) and the National Cancer Institute (NCI P30 CA125123-03). This paper is subject to the NIH Public Access Policy.

\section{References}

Borsheim KY, Bratbak G, Heldal M. Enumeration and biomass estimation of planktonic bacteria and viruses by transmission electron microscopy. Appl. Environ. Microbiol 1990;56:352-356. [PubMed: 2306088]

Cox MMJ. Cell-based protein vaccines for influenza. Curr. Opin. Mol. Ther 2005;7:24-29. [PubMed: 15732526]

Cox MMJ. Progress on baculovirus-derived influenza vaccines. Curr Opin Mol Ther 2008;10:56-61. [PubMed: 18228182]

Darling AJ, Boose JA, Spaltro J. Virus assay methods: accuracy and validation. Biologicals 1998;26:105-110. [PubMed: 9811514]

Dutton G. In-line analytics improve manufacturing. Gen. Eng. Biotech. News 2008;28:1-4.

Hitchman RB, Siaterili EA, Nixon CP, King LA. Quantitative Real-Time PCR for rapid and accurate titration of recombinant baculovirus particles. Biotech. and Bioeng 2007;96:810-814.

Holtz KM, Anderson DK, Cox MMJ. Production of a recombinant influenza vaccine using the baculovirus expression vector system. Bioprocessing 2003;2:25-32.

Hopkins RF, Esposito D. A rapid method for titrating baculovirus stocks using the Sf-9 Easy Titer cell line. BioTechniques 2009;47:785-788. [PubMed: 19852765]

Jorio H, Tran R, Kamen A. Stability of serum-free and purified baculovirus stocks under various storage conditions. Biotechnol. Prog 2006;22:319-325. [PubMed: 16454526]

Kost TA, Condreay JP, Jarvis DL. Baculovirus as versatile vectors for protein expression in insect and mammalian cells. Nature Biotech 2005;23:567-575.

Knipe, DM.; Howley, PM. Fields Virology. Philadelphia, PA: Lippincott, Williams and Wilkins; 2007.

Lo HR, Chao YC. Rapid titer determination of baculovirus by quantitative real-time polymerase chain reaction. Biotechnol. Prog 2004;20:354-360. [PubMed: 14763863]

Lynn DE. Improved efficiency in determining the titer of the Autographa californica baculovirus nonoccluded virus. BioTechniques 1992;13:282-285. [PubMed: 1389161]

Mahy, BWJ.; Kangro, HO. Virology Methods Manual. San Diego, CA: Academic Press; 1996.

Nettleship JE, Assenberg R, Diprose JM, Rahman-Huq N, Owens RJ. Recent advances in the production of proteins in insect and mammalian cells for structural biology. J. of Struct. Biol. 2010 (in press).

O'Reilly, DR.; Miller, LK.; Luckow, VA. Baculovirus Expression Vectors: A Laboratory Manual. New York, N.Y.: Oxford University Press; 1994. 
Rodda SJ, Gallichio HA, Hampson AW. The single radial immunodiffusion assay highlights small antigenic differences among influenza virus hemagglutinins. J Clin. Microbiol 1981;14:479-482. [PubMed: 6171580]

Roldão A, Oliveira R, Carrondo MJT, Alves PM. Error assessment in recombinant baculovirus titration: Evaluation of different methods. J. Virol. Methods 2009;159:69-80. [PubMed: 19442848]

Shen CF, Meghrous J, Kamen A. Quantitation of baculovirus particles by flow cytometry. J. Virol. Methods 2002;105:321-330. [PubMed: 12270664]

Stoffel CL, Rowlen KL. Design and characterization of a compact dual channel virus counter. Cytometry A 2005a;65:140-147. [PubMed: 15830378]

Stoffel CL, Finch R, Christensen K, Edwards D, Rowlen KL. Rapid determination of baculovirus titer by a dual channel virus counter. American Biotech. Lab 2005b;37:24-25.

Summers MD, Smith GE. A manual of methods for baculovirus vectors and insect cell culture procedures. Texas Agricultural Experiment Station Bulletin 1987;B1555:1-56.

Trowitzsch S, Bieniossek C, Nie Y, Garzoni F, Berger I. New baculovirus expression tools for recombinant protein complex production. J. of Struct. Biol. 2010 (in press).

Tsai CT, Chan ZR, Lu JT, Yang DG, Lo WH, Hu YC. Factors influencing the production and storage of baculovirus for gene delivery: an alternative perspective from the transducing titer assay. Enzyme Microb Tech 2007;40:1345-1351.

Wang K, Holtz KM, Anderson K, Chubet R, Mahmoud W, Cox MMJ. Expression and purification of an influenza hemagglutinin--one step closer to a recombinant protein-based influenza vaccine. Vaccine 2006;24:2176-2185. [PubMed: 16310896] 


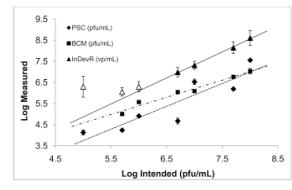

Figure 1. Comparison of log-scale assay results for samples diluted in PSFM

Data points represent the mean measured result of samples 1a-7a with error bars representing $\pm 1 \sigma$ from the mean. Within the Virus Counter data set (triangles), the lowest three values are shown as unfilled triangles to indicate that these values were below the SQL determined for PSFM and were not included in the linear regression fit to the data. Coefficients of determination $\left(\mathrm{R}^{2}\right)$ for linear regression fits to the data were 0.81 for Protein Sciences Corporation (diamonds with a dashed line), 0.97 for Baylor College of Medicine (squares with a dot-dash line) and 1.0 for InDevR (triangles with a solid line). Slopes of the regression fits were $1.1 \pm 0.2$ for Protein Sciences Corporation, $0.81 \pm 0.07$ for Baylor College of Medicine and 1.2 \pm 0.1 for InDevR. Pearson correlation coefficients for the Virus Counter, Protein Sciences Corporation and Baylor College of Medicine were $\mathrm{r}=0.94$ ( $\mathrm{p}<$ $0.01), r=0.90(p<0.01)$ and $r=0.99(p<0.001)$, respectively. 


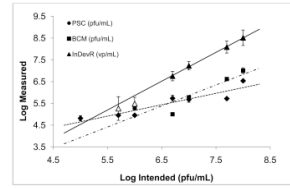

Figure 2. Comparison of log-scale assay results for samples diluted in SDB

Data points represent the mean measured result of samples $1 \mathrm{~b}-7 \mathrm{~b}$ with error bars representing $\pm 1 \sigma$ from the mean. Within the Virus Counter data set (triangles), results for samples $5 \mathrm{~b}$ and $6 \mathrm{~b}$ are shown as unfilled triangles to indicate that these values were below the SQL determined for SDB and were not included in the linear regression fit to the data. Sample $7 b$ returned a zero count and is not included in the figure or the regression fit to the data. Coefficients of determination $\left(\mathrm{R}^{2}\right)$ for the linear regressions fits to the data were 0.85 for Protein Sciences Corporation (diamonds with a dashed line), 0.82 for Baylor College of Medicine (squares with a dot-dash line) and 1.0 for InDevR (triangles with a solid line). Slopes of the regression fits were $0.5 \pm 0.1$ for Protein Sciences Corporation, $1.0 \pm 0.3$ for Baylor College of Medicine and $1.32 \pm 0.04$ for InDevR. Pearson correlation coefficients for the Virus Counter, Protein Sciences Corporation and Baylor College of Medicine were $r=1$ $(\mathrm{p}<0.001), \mathrm{r}=0.92(\mathrm{p}<0.01)$ and $\mathrm{r}=0.90(\mathrm{p}<0.05)$, respectively. 


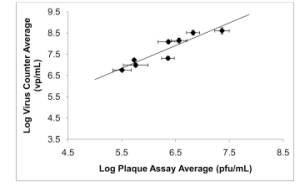

Figure 3. A log-scale correlation of Virus Counter and plaque assay results

Mean results for all samples above SQL (i.e. both PSFM and SDB) are shown. Mean plaque assay results are the combined results from Baylor College of Medicine and Protein Sciences Corporation. Error bars represent the standard error of the mean. The solid line represents a linear regression fit to the data and was obtained with a coefficient of dertermination $\left(\mathrm{R}^{2}\right)$ of 0.86 and a slope of $1.1 \pm 0.2$. The Pearson correlation coefficient was determined to be $0.93(\mathrm{p}<0.001)$. 
Table 1

Summary of Samples and Results

\begin{tabular}{|c|c|c|c|c|}
\hline Sample ID ${ }^{a}$ & $\begin{array}{c}\text { Intended } \\
\text { Titer } b \\
\text { (pfu/mL) }\end{array}$ & $\begin{array}{l}\text { InDevR } \\
(\mathrm{vp} / \mathrm{mL})\end{array}$ & $\begin{array}{c}\text { PSC } \\
(\mathbf{p f u} / \mathbf{m L} \mathbf{L})\end{array}$ & $\begin{array}{c}\text { BCM } \\
(\mathbf{p f u} / \mathbf{m L})\end{array}$ \\
\hline $1 \mathrm{a}$ & $1 \times 10^{8}$ & $(4 \pm 3) \times 10^{8}$ & $(3.6 \pm 0.4) \times 10^{7}$ & $(1.1 \pm 0.3) \times 10^{7}$ \\
\hline $2 \mathrm{a}$ & $5 \times 10^{7}$ & $(1.4 \pm 0.9) \times 10^{8}$ & $(1.60 \pm 0.05) \times 10^{6}$ & $(5.8 \pm 0.3) \times 10^{6}$ \\
\hline $3 \mathrm{a}$ & $1 \times 10^{7}$ & $(2.1 \pm 0.9) \times 10^{7}$ & $(3 \pm 1) \times 10^{6}$ & $(1.2 \pm 0.2) \times 10^{6}$ \\
\hline $4 \mathrm{a}$ & $5 \times 10^{6}$ & $(1.0 \pm 0.5) \times 10^{7}$ & $(5 \pm 2) \times 10^{4}$ & $1.1 \times 10^{6}$ \\
\hline $5 \mathrm{a}$ & $1 \times 10^{6}$ & $<\mathrm{SQL}^{c}$ & $(8 \pm 1) \times 10^{4}$ & $3.7 \times 10^{5}$ \\
\hline $6 a$ & $5 \times 10^{5}$ & $<\mathrm{SQL}^{c}$ & $(1.7 \pm 0.2) \times 10^{4}$ & $1.0 \times 10^{5}$ \\
\hline $7 \mathrm{a}$ & $1 \times 10^{5}$ & $<\mathrm{SQL}^{c}$ & $(1.3 \pm 0.4) \times 10^{4}$ & $-d$ \\
\hline $1 b$ & $1 \times 10^{8}$ & $(3 \pm 2) \times 10^{8}$ & $(3.4 \pm 0.3) \times 10^{6}$ & $(1.0 \pm 0.2) \times 10^{7}$ \\
\hline $2 b$ & $5 \times 10^{7}$ & $(1.2 \pm 0.6) \times 10^{8}$ & $(5 \pm 1) \times 10^{5}$ & $(4.1 \pm 0.2) \times 10^{6}$ \\
\hline $3 b$ & $1 \times 10^{7}$ & $(1.7 \pm 0.4) \times 10^{7}$ & $(4.8 \pm 0.3) \times 10^{5}$ & $6.0 \times 10^{5}$ \\
\hline $4 b$ & $5 \times 10^{6}$ & $(6 \pm 2) \times 10^{6}$ & $(5.4 \pm 0.9) \times 10^{5}$ & $1.0 \times 10^{5}$ \\
\hline $5 b$ & $1 \times 10^{6}$ & $<\mathrm{SQL}^{c}$ & $(9 \pm 1) \times 10^{4}$ & $2.0 \times 10^{5}$ \\
\hline $6 b$ & $5 \times 10^{5}$ & $<\mathrm{SQL}^{c}$ & $(9.0 \pm 0.9) \times 10^{4}$ & $-d$ \\
\hline $7 b$ & $1 \times 10^{5}$ & $-d$ & $(7 \pm 1) \times 10^{4}$ & $-d$ \\
\hline$(+)$ control & $1.7 \times 10^{8}$ & $(1.1 \pm 0.5) \times 10^{9}$ & $(8 \pm 1) \times 10^{7}$ & $(5.7 \pm 0.9) \times 10^{7}$ \\
\hline PSFM (-) control & N/A & Used to determine SQL & $-d$ & $-d$ \\
\hline SDB (-) control & N/A & Used to determine SQL & $-d$ & $d$ \\
\hline
\end{tabular}

${ }^{a}$ The letter within the sample ID indicates the diluent used. Un-blinding of the samples indicated that diluent "a" was PSFM growth medium and diluent "b" was SDB.

${ }^{b}$ Intended titer values were determined from dilution of a baculovirus stock, which had been previously titered by plaque assay.

${ }^{c}$ Indicates values that were below the Virus Counter's measured SQL for the corresponding diluent $\left(3.1 \times 10^{6}\right.$ and $7.8 \times 10^{5}$ vp/mL for PSFM and SDB, respectively).

$d_{\text {Indicates an uncountable or zero count for that sample. }}$ 